\title{
Empty Verbs in Chinese Predicatives and Complex Predicates*
}

\author{
Niina Ning Zhang \\ Zentrum für Allgemeine Sprachwissenschaft \\ zhang@zas.gwz-berlin.de
}

\begin{abstract}
This paper investigates syntactic properties of verbless constructions in Chinese. Verbless constructions differ from contructions with overt verbs in three major respects. First, there is a VP-internal nominal raising in Chinese, which is optional if an overt verb shows up, and obligatory if there is no overt verb. Second, while an overt verb can select various kinds of argument, the internal argument of a verbless construction cannot be indefinite. Third, there are two types of object depictive secondary predication constructions, and only one of them allows for a null verb.
\end{abstract}

\section{Introduction}

Since Chao (1988), it has been assumed that there is no verb gapping construction in Chinese. However, the data provided by Paul (1996) and Zhang (1997) explicitly indicate that Chinese has verbless constructions, regardless of whether they are called gapping or not, as shown in (1):

(1) a. ta qu-le Beijing san tang, wo Ø Shanghai si tang. he go-ASP Beijing three CL I Shanghai four CL

'He has been to Beijing three times, and I to Shanghai four times.'

b. ni dasao zhei jian fangzi, wo $\varnothing$ nei jian. ${ }^{1}$ you clean this-one $\mathrm{CL}$ room I that-one $\mathrm{CL}$ 'You clean this room, and I that one.'

In this paper, I will show that the occurrence of a null verb can trigger an obligatory predicate-internal nominal raising, that the occurrence of a null verb is restricted by the specificity of its selected nominal, and that null verbs are always absent in a certain type of secondary predication construction.

In section 2, I introduce VP-internal NP raising in predicative nominals, and show that the raising is obligatory in copulaless predicative constructions. This contrast between verbless constructions and constructions with overt verbs is further manifested in nonpredicative construction, as illustrated in section 3. In section 4, I introduce another contrast: an indefinite internal argument can be selected by an overt verb, but not by an empty verb. A further contrast between verbless constructions and constructions with overt verbs is presented in section 5: there are two types of object depictive secondary predication constructions, only one of them allows empty verbs. I conclude this paper in section 6 .

\footnotetext{
* Earlier versions of this paper benefited from comments made by Daniel Hole, Kerstin Schwabe, and Danqing Liu. I am grateful to all of them. The greatest debt of all I owe to the particularly detailed and thoughtful comments given by Ewald Lang.

'Zhei is a contraction form of the demonstrative zhe 'this' and the numeral $y i$ 'one', and nei is a contraction form of the demonstrative $n a$ 'that' and the numeral $y i$ 'one' (Zhu 1984: 85, among others).
} 


\section{VP-internal NP raising in predicative constructions}

In this section I propose that there is a local NP-raising to account for the fact that a Chinese predicative nominal may occur with a numeral and a classifier at its right peripheral position.

\subsection{The occurrence of right peripheral numerals and classifiers}

In Chinese, an NP is usually preceded by a numeral and a classifier, as in (2a). However, NPs in non-equative predicatives can not only stand alone without a numeral and a classifier to the left, as shown in (2c) and (3a), but can also have a numeral and a classifier occurring to the right, as shown in (2b) and (3b).

(2) a. Xiao Hu shi yi ge taoqi-gui.

$\mathrm{Xiao} \mathrm{Hu}$ be one CL naughty-spirit

'Xiao $\mathrm{Hu}$ is a naughty person.'

b. Xiao Hu (shi) taoqi-gui yi ge.

$\mathrm{Xiao} \mathrm{Hu}$ be naughty-spirit one $\mathrm{CL}$

'Xiao $\mathrm{Hu}$ is a naughty person.'

c. Xiao $\mathrm{Hu}$ shi taoqi-gui.

Xiao $\mathrm{Hu}$ be naughty-spirit

'Xiao $\mathrm{Hu}$ is a naughty person.'

(3) a. wo ma [sc ta da bendan].

I scold he big fool

'I scolded him a big fool.'

b. wo ma [sc ta da bendan yi ge].

I scold he big fool one $\mathrm{CL}$

'I scolded him a big fool.'

Notice that the predicative nominals in $(2 a)$ and $(2 b)$ do not differ in either their specificity or quantity meaning. It is thus possible that the different forms are transformationally related. I propose that NP-initial predicative nominals, as in (2b), are derived from the corresponding numeral-initial nominals, as in (2a), by NP raising. For instance, in (2b), the NP taoqi-gui 'naughty-spirit' is raised to the left of the numeral $y i$ 'one'.

(2c) does not have a numeral and classifier, thus it may have different numerations and thus different derivations from that of (2a) and (2b). Similarly, nor is (3a) related to (3b) derivationally.

The VP-internal NP raising is optional if the lexical meaning of the NP presupposes either a negative judgment, as in (2) and (3) above, or a positive judgment, as in (4a) below. One might feel that the undeleted form sounds more vivid. If the lexical meaning of the NPs in NP-initial predicative nominals does not presuppose either a negative or positive judgment, as in (4b) and (4c) below, the VP-internal NP raising is blocked. (yi ge in (4c) cannot occur to the left of shenme either. I will discuss this issue in section 2.3) 
(4) a. wo shi nanzihan yi ge.

I be male-man one $\mathrm{CL}$

'I am a man.' (proudly)

b. ta shi Yazhouren (*yi ge).

he be Asian one CL

'He is an Asian.'

c. ni dang [sC ta shenme ren (*yi ge)]?

you consider he what person one $\mathrm{Cl}$

'What kind of person do you consider him to be?'

It thus seems that VP-internal NP raising as a syntactically possible operation is constrained by non-syntactical factors.

\subsection{The syntactic categories of predicative nominals}

In the literature on nominal structures, it has been claimed that an argument nominal must have a DP projection, while a non-argument one such as a predicative nominal needs not (Longobardi 1994: 612, 621). To show this point, Radford (1997: 156) gives the following English example, where a predicative nominal is determinerless:

(5) Dick Head is head of department.

Chierchia (1998) claims that this is only true of a certain type of languages such as French. In a different type of languages such as Chinese, it is widely-known that bare NPs can be arguments. Now the question is what kind of syntactic categories predicative nominals can be in Chinese. The following data show that both bare NPs and DPs headed by demonstratives can be predicatives. The latter are definite predicatives, occurring in equative predicative constructions.

(6) a. renjia dou gongchengshi le, ni cai jishuyuan. others already engineer ASP, you only technician

(Ma 1991)

'While others are already engineers, you are just a technician.'

b. Xiao Li jiu shi nei ge qiong xuesheng. ${ }^{2}$

Xiao Li exactly be that-one CL poor student

'Xiao Li is the poor student.'

If an argument is numeral-initial, according to $\mathrm{Li}$ (1998), it can be either an individualdenoting DP, with a null indefinite $\mathrm{D}$, or a quantity-denoting NumP:

$$
\begin{array}{ll}
\text { a. } & \left.\left[{ }_{D P}\left[\text { NumP }\left[\mathrm{ClP}_{\mathrm{NPP}}\right]\right]\right]\right] \\
\text { b. } & {\left[\text { NumP }\left[\mathrm{ClP}_{\mathrm{NPP}}[]\right]\right.}
\end{array}
$$$$
(\mathrm{ClP}=\text { Classifier Phrase })
$$

The two possibilities can also be found in predicative nominals. Li (1998) argues that NumP exclusively encodes quantities. This is explicit in the contrast between the two interpretations of (8). The scope of the quantity adverb cai 'only' is the NP rather than the

\footnotetext{
${ }^{2}$ The adverb jiu 'exactly' expresses certainty when it occurs with verbs like shi 'be', you 'have', zai 'be at', and xiang 'be similar to' (Hou 1998: 348).
} 
numeral in (i), and is the numeral in (ii). Accordingly, we assume that the numeral-initial nominal is a DP with a null indefinite D in (i), and a NumP in (ii).
women cai shi yi ge yanjiu xiao-zu.
we only be one CL research small-group
i. 'We are only a research group (not a research institute yet)'
ii. 'We are only one research group (not two yet)' ( $y i$ has a contrastive stress)

Since the quantity meaning of reading (i) of (8) is not salient, the numeral $y i$ 'one' is optional under this reading. However, the classifier ge is still obligatory. I have no explanation of the occurrence of the classifier here. In contrast to reading (i), reading (ii) requires both the numeral $y i$ 'one' and the classifier ge. I thank Ewald Lang for bringing my attention to this contrast.

In the following equative predicative data, the predicatives are proper nouns. According to Li (1999), proper nouns are base-generated at definite $\mathrm{D}$. Thus the predicatives are DPs:
aya, dou Fudan
le! wo dang xia yi zan cai Dabasi.

Oh already Fudan-university ASP I consider next one stop only Dabasi

'Oh, it's already Fudan University! I thought it to be only Dabasi next stop.'

(On a bus. Dabasi is a place two bus-stops away from Shanghai Fudan Univ.)

We thus conclude that like argument nominals, predicative nominals in Chinese can also be NPs, DPs, and NumPs.

\subsection{VP-internal NP raising in copulaless predicative constructions}

In this section I will show that the VP-internal NP raising introduced in section 2.1 is obligatory in the presence of an empty copula.

In a copulaless construction such as the one in (10), a predicative nominal cannot be preceded by a numeral and a classifier (S. Tang 1998):

\footnotetext{
a. wo (*yi ge) Zhongguoren.$$
\text { I one } \mathrm{CL} \text { Chinese }
$$$$
\text { 'I am a Chinese.' }
$$

b. wo ma [sc ta (*yi ge) bendan].

I scold he one CL fool

'I scolded him a fool.'
}

As pointed out by S. Tang (1998), the grammaticality contrast between the presence and absence of a copula with respect to the occurrencce of a numeral-initial predicative nominal indicates that the absence of the copula is not simply the result of a PF deletion. I will adopt Kayne's $(1994: 65,136,145)$ hypothesis that a small clause has an empty verbal head, and extend this hypothesis to Chinese copulaless matrix predicative constructions, claiming that such constructions also have an empty copula. ${ }^{3}$

\footnotetext{
${ }^{3} \mathrm{~S}$. Tang (1998) assumes that in both small clauses and matrix predicative constructions the predicative nominals are $\mathrm{N}^{0}$ elements and subject nominals are Spec or adjunct elements of the NP headed by the predicative nominals. Thus in his approach, the whole small clauses or matrix predicative constructions are bare NPs. This
} 
The ban on numeral-initial predicative nominals in the absence of an overt copula can also be seen in a conjunction construction:

(11) a. ta Zhongguoren, wo Deguoren.

he Chinese I German

'He is a Chinese (and) I am a German.'

b. ta shi yi ge Zhongguoren, wo*(shi) yi ge Deguoren.

he be one CL Chinese I be one CL German

'He is a Chinese (and) I am a German.'

Data like (10) and (11) suggest that if an empty copula is present, VP-internal NP raising to the left of a numeral is obligatory. Presumably, Chinese empty copulas trigger an obligatory NP raising. In contrast, if an overt copula is present, VP-internal NP raising is optional, as shown in (2) above.

Notice that the neutral-judgment blocking effect on VP-internal NP raising discussed in section 2.1 holds regardless of whether the copula is overt or null:
a. ta (shi) Yazhouren $(*$ yi ge).
he be Asian one $\mathrm{CL}$
'He is an Asian.'
b. ni dang [sc ta shenme ren (*yi ge)]?
you consider he what person one $\mathrm{CL}$
'What kind of person do you consider him to be?'

\subsection{Empty copulas and WH predicative nominals}

The absence of left peripheral numerals and classifiers with empty copulas observed above is also seen in WH nominals.

There are syntactic asymmetries between the Chinese WH nominals shei 'who' and shenme 'what' (Lü et al. 1980). Firstly, shenme can directly merge with another nominal to form a larger nominal, which can have either a [+ human] or a [-human] feature, as in (13). In contrast, shei can never merge with another nominal directly to form a larger nominal, as shown in (14).
a. na shi shenme dongxi?
that be what thing
'What is that?'
b. ta shi shenme ren?
he is what person
'What kind of person is he?'

approach cannot explain the occurrence of numerals and classifiers to the right of NPs in predicative nominals. For a review of S. Tang's approach, see Zhang (To appear b).

${ }^{4}$ Zhu (1984: 89) has the following examples, where the possessive marker de is elided between shei and the nominal following it:
(i) ta shi qi shei de zixingche qu de? he be ride who DE bike go PART 'Whose bike did he ride to go there?'
(ii) ni ba shei de yanjing dapo le? you BA who DE glasses break ASP 'Whose glasses have you broken?'



a. $\quad *$ na shi shei dongxi?
that be who thing
b. $\quad$ ta shi shei ren?
he be who person

Secondly, shenme can be preceded by a numeral and a classifier, while shei cannot:
a. ta mai-le san ge shenme (dongxi)?
he buy-ASP three CL what thing
'What three things has he bought?'
b. ta kanjian-le san ge $\{*$ shei/shenme ren $\}$ ?
he see-ASP three CL who/what person
'What kind of person are the three persons whom he saw?'

The asymmetries can be accounted for by assuming that shei, like other personal

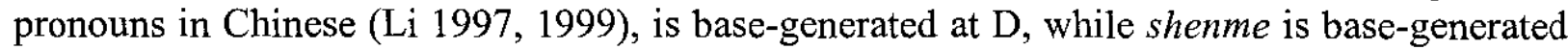
at $\mathrm{N}$. Like a regular noun in Chinese, shenme can be used as an attribute of another noun, and can be preceded by a numeral and a classifier. Shenme differs from regular common nouns in that it cannot be modified by an adjective and that it has an unspecific feature. Thus, unlike other Chinese nouns, shenme and proper nouns share two properties: neither can be modified by APs and both have intrinsic specificity features. Proper nouns are specific, while shenme is nonspecific.

If shenme is a noun, we expect it to behave like other nouns with respect to the occurrence restriction on preceding numerals and classifiers when it is used as a predicative. This is borne out. When there is an overt copula, a numeral and a classifier are optional to the left of shenme, while when there is no overt copula, nothing can precede shenme:

$$
\begin{aligned}
& \text { a. na shi (yi ge) shenme (dongxi)? } \\
& \text { that be one CL what thing } \\
& \text { 'What is that?' } \\
& \text { b. ni ma ta (*yi ge) shenme? } \\
& \text { you scold he one CL what } \\
& \text { 'What did you scold him?' }
\end{aligned}
$$

Summarizing, I have shown that there is a VP-internal NP raising in Chinese predicative constructions, which is optional if an overt copula shows up, and obligatory if there is no overt copula.

\section{VP-internal nominal raising in non-predicative constructions}

\subsection{Optional VP-internal nominal raising in the presence of an overt verb}

In Chinese nominals, although the choice of classifier is determined by the noun, "nearly all individual-denoting nouns, regardless of whether they have their own classifiers, can be counted by the classifier ge" (Zhu 1982: 49). In Zhang (1999b) I show that in Chinese, eventuality counting is similar to individual counting in that while there are general classifiers such as $c i$ and $h u i$, the choice of an alternative classifier is determined by the eventuality type 
denoted by the verbal phrase. In other words, like individual counting, which requires a match between a classifier and the individual type expressed by the noun, eventuality counting in Chinese also requires a match between a classifier and the eventuality type expressed by the predicate. For instance, the oral communication events denoted by verbs such as gaosu 'tell', and jiao 'call, shout' use the word sheng 'sound' as their classifier, as shown in (17a); and telic motion eventualities use the classifier tang, as shown in (17b):
a. ta jiao-le ni san sheng.
he call-ASP you three CL(sound)
'He called you three times.'
b. ta qu-le Meiguo liang tang.
ta go-ASP USA two CL
'He has been to USA twice.'

To account for this type of eventuality counting I proposed (18a), which is parallel to the nominal structure (18b) as proposed by Li $(1997,1998)$ :
a. $\quad[\mathrm{vP}[\mathrm{Nump}[\mathrm{CIP}[\mathrm{vP}]]]]$
b. $\left.\quad\left[{ }_{D P}\left[\mathrm{NumP}_{\mathrm{ClP}}[\mathrm{NP}]\right]\right]\right]$

In both (18a) and (18b) the top projection is a functional projection, vP and DP, respectively. (18a) can explain the predicate-classifier matching fact. In both (18a) and (18b) a classifier in the head of CIP selects its appropriate semantic type of complement. In addition, according to S. Tang (1998), Chinese verbs overtly move from $\mathrm{V}$ to $\mathrm{v}$, thus a verb occurs to the left of an eventuality quantity (frequency or duration) expression. ${ }^{5}$

In Zhang (1999b) I described various syntactic properties of eventuality quantity expressions. Here I introduce two of them relevant to the present issue. First, an eventuality quantity expression can follow the expletive $t a(\mathrm{ge})$ ' it'. 6

a. ni jiu pao ta yi tang Beijing ba! you then run it one $\mathrm{CL}$ Beijing IMP

'Then make a trip to Beijing!'

b. wo xiang wanr ta (ge) san ge yue.

I want play it three CL month

'I want to play for three months.'

Second, an eventuality quantity expression can occur either to the left or to the right of a proper noun and a nominal with a demonstrative. There is no meaning change between a and $b$ in the following pairs.
a. ta ti-le nei zhi mao yi jiao.
he kick-ASP that-one CL cat one CL'foot'
'He gave that cat a kick.'
b. ta ti-le yi jiao nei zhi mao.

\footnotetext{
${ }^{5}$ An additional assumption required here is that head movement is not blocked if the crossed heads do not share any feature with the target head. Specifically, in (18a) the v of vP shares no feature with either $\mathrm{Cl}$ or Num. Thus the movement of a verb from $\mathrm{V}$ to $\mathrm{v}$ across $\mathrm{Cl}$ and $\mathrm{Num}$ is possible. This assumption has independent evidence in the interactions between focus and interrogative elements in Chinese (section 3.3 of Zhang (To appear a)).

${ }^{6}$ The expletive $t a$ ( $g e$ ) 'it' is labelled as $x u z h i-b i n y u$ 'empty-referential object' in Ma (1983), and is assumed to be base-generated at Spec of VP in Lin (1993).
} 
(21) a. ta qu-le Beijing yi tang. he go-ASP Beijing one $\mathrm{CL}$ 'He made a trip to Beijing.'

(22) a. ta biaoyang-le Lao Li wu fenzhong. he praise-ASP Lao Li five minute 'He praised Lao Li for five minutes.'

b. ta biaoyang-le wu fenzhong $\underline{\mathrm{Lao} \mathrm{Li}}$.

The expletive fact and the free order fact with respect to a proper noun or a demonstrative initial nominal are related. The occurrence of an expletive to the left of a numeral indicates that there is a phrasal position available at this point of the derivation. It can be either Spec of NumP or Spec of another functional projection between $\mathrm{vP}$ and NumP. In the absence of evidence for the latter case, I simply assume that the position of an expletive is Spec of NumP. Since an expletive cannot be immediately followed by a non-numeral element, as shown in (23b) and (24b), I assume that an expletive and a pre-numeral definite nominal (a proper noun or a demonstrative initial nominal) take the same position.

a. ni jiu pao ta yi tang Beijing ba! you then run it one CL Beijing IMP

$$
[=(19 a)]
$$

'Then make a trip to Beijing!'

b. *ni jiu pao ta Beijing yi tang ba.

a. wo xiang guang ta liang xiaoshi Nanjing-Lu.

I want stroll it two hour Nanjing-Road

'I want to stroll around Nanjing Road for two hours.'

b. *wo xiang guang ta Nanjing-Lu liang xiaoshi.

Now let us see what happens when an expletive and a pre-numeral definite nominal take the same position: if an expletive is present, the definite nominal must occur to the right of an eventuality quantity expression, i.e. stay in situ, as shown by Beijing in (23a) and Nanjing- $L u$ in (24a); in contrast, if there is no expletive, it is possible that the definite nominal raises to Spec of NumP, i.e. to the left of the numeral, as shown by the definite nominals in (20a), (21a), and (22a). The pairs in (20), (21), and (22) tell us that the optional raising of the definite nominals occurs with overt verbs.

\subsection{Obligatory VP-internal nominal raising in the absence of an overt verb}

I have shown that in the presence of an overt verb an eventuality quantity expression can occur either to the left or to the right of a proper noun or a nominal with a demonstrative, see (20) to (22). However, in coordination constructions, if the verb in the second conjunct is gapped, a proper noun or a nominal with a demonstrative has to occur to the left of the eventuality quantity expression, see (25a, 26a) vs. (25b, 26b):

(25) a. ta qu-le Beijing san tang, wo Shanghai si tang. he go-ASP Beijing three CL I Shanghai four CL 'He has been to Beijing three times, and I to Shanghai four times.'

b. *ta qu-le san tang Beijing, wo si tang Shanghai. he go-ASP three CL Beijing I four CL Shanghai 
c. ta qu-le san tang Beijing, wo qu-le si tang Shanghai. he go-ASP three CL Beijing I go-ASP four CL Shanghai 'He has been to Beijing three times, and I to Shanghai four times.'

(26) a. ta dasao-le zhei jian fangzi san ci, wo nei jian fangzi si ci. he clean-ASP this-one CL room three CL I that-one CL room four CL 'He cleaned this room three times, and I that room four times.'

b. *ta dasao-le san ci zhei jian fangzi, wo si ci nei jian fangzi. he clean-ASP three $\mathrm{CL}$ this-one $\mathrm{CL}$ room I four $\mathrm{CL}$ that-one $\mathrm{CL}$ room

c. ta dasao-le san ci zhei jian fangzi, wo dasao-le si ci nei jian fangzi. he clean-ASP $3 \mathrm{CL}$ this-one $\mathrm{CL}$ room I clean-ASP $4 \mathrm{CL}$ that-one $\mathrm{CL}$ room 'He cleaned this room three times, and I that room four times.'

If the occurrence of a nominal to the left of an eventuality quantity expression is derived by raising of the nominal, as argued in the last subsection, the above data indicate that this raising is obligatory in the absence of an overt verb.

Summarizing, I have shown that there is a VP-internal definite nominal raising in Chinese non-predicative constructions, and that this raising is optional if an overt verb shows up, and obligatory if there is no overt verb.

\section{The definiteness effect on the subcategorization of null verbs}

In this section we examine the specificity of internal arguments selected by null verbs.

In Chinese, a numeral initial argument is ambiguous between a quantity salient meaning and an existential meaning, which is quantity insalient, as shown in (27a). As noted by S. Tang (1998: 211), in verbless constructions, the quantity meaning of a numeral must be salient, as shown in (27b) and (27c).

a. ta you yi fu you-hua.

he have one $\mathrm{CL}$ oil-painting

i. 'He has an oil-painting." (The quantity meaning is not salient.)

ii. 'He has one oil-painting.' (The quantity meaning is salient.)

b. ta yi fu you-hua.

he one CL oil-painting

i. *'He has an oil-painting.'

ii. 'He has one oil-painting.'

c. ta chi-le liang ge pingguo, wo si ge juzi.

he eat-ASP two CL apple I four CL orange

'He ate two apples and I four oranges.' (The quantity meaning is salient.)

Numeral-initial internal arguments with quantity salient meaning can be either NumPs, as assumed by Li (1998), or derived from a secondary predication construction, as argued by Zhang (1999a). ${ }^{8}$ This dispute, however, is irrelevant to the present issue. The above data show

\footnotetext{
${ }^{7}$ Notice that although the quantity meaning denoted by yi fu 'one CL' is not salient under reading (i) of (27), the absence of $y i$ fu implies the quantity can be more than one. This is different from the case of the predicative construction shown by $(2 \mathrm{c})$.

${ }^{8}$ In Zhang (1999a) I argue that only external arguments and predicatives can be NumPs, and that there is no internal argument NumP in Chinese.
} 
that empty verbs can select numeral-initial nominals with salient quantity meaning, but not those with quantity insalient and existential meaning.

Notice that in Chinese a bare NP can be kind-denoting, as in (28a), or indefinite, as in (28b). Tang's (1998: 125) example quoted as (28c) shows that such a nominal cannot occur in a verbless construction either. Notice that the two occurrences of the eventive classifier $c i$ in (28a) are linked to the verb chi-guo 'eat-ASP' rather than to the nominal luotuo-rou 'camelmeat' or ye-tu-rou 'wild-hare-meat' respectively. Thus $c i$ is not within the object nominals.

(28) a. wo chi-guo liang ci luotuo-rou, ta $\varnothing$ san ci ye-tu-rou.

I eat-ASP two CL camel-meat he three CL wild-hare-meat

'I have eaten camel-meat twice, and he wild-hare-meat three times.'

b. wo he-wan-le tang jiu zou le.

I drink-finish-ASP soup then go ASP

'I left after I finished drinking of the soup.'

c. *wo he-wan-le tang, ni $\varnothing$ qishui.

I drink-finish-ASP soup you soft-drink

'I finished the soup, you soft drink.'

As noted by S. Tang, the presence of the perfective aspect suffix le and the resultative verb wan 'finish' makes the bare NPs in (28b) and (28c) have an existential reading, and thus (28) gives us the same information as (27) does: indefinite arguments cannot occur in a verbless construction, regardless of whether they are numeral-initial DPs or bare NPs.

The above data tell us that empty verbs can select kind-denoting bare NP nominals, but not existential denoting bare NP nominals. The following data show that empty verbs can select definite nominals:

(29) ni dasao zhei jian fangzi, wo Ø nei jian.

you clean this-one $\mathrm{CL}$ room I that-one CL

'You clean this room, and I that one.'

In this section I have presented data showing that Chinese empty verbs select numeralinitial nominals with salient quantity meaning, kind-denoting bare NP nominals, and definite nominals, ${ }^{9}$ but not indefinite nominals, regardless of whether they are numeral-initial nominals or bare NPs.

\section{The absence of a verb in secondary predication constructions}

In this section I show that there are two types of object depictive secondary predication in Chinese, and that only one of them allows for a null verb.

\footnotetext{
${ }^{9}$ There are some finer constraints on the occurrence of these three types of nominals with empty verbs. See Paul (1996) and S. Tang (1998) for more discussion.
} 


\subsection{The two types of object depictive secondary predication}

J. Tang (1996: 472) treats the following (30a) as the same construction to (30c), while Huang (1994: 31) treats the following (30b) as the same construction to (30c). ${ }^{10}$
a. wo mai-le yi ben bijibu sanshi ye.
I buy-ASP one CL note-book thirty page
'I bought a notebook, which has thirty pages.'
b. wo mai-le yi ben shu hen youqu.
I buy-ASP one CL book very interesting
'I met a book, which is very interesting.'
c. wo mai-le bijibu shiben.
I buy-ASP notebook ten $\mathrm{CL}$
'I bought ten notebooks.'

These three sentences share a property: the final NumP or AP is a predicate of the direct object. However, there are at least five aspects differentiating c-type sentences from the a-type and b-type sentences.

In Chinese, only definite and kind-denoting nominals can undergo topicalization and a contrastive-focus related object shift, as shown in (31):

(31) a. wo kan-le $\{$ zhei/yi $\} \quad$ ben shu. I read-ASP this-one/one CL book 'I read this/a book.'

b. $\quad\{$ zhei/*yi $\}$ ben shu wo kan-le. this-one/one CL book I read-ASP

c. wo $\{\underline{z h e i} / *$ yi $\}$ ben shu kan-le.

I this-one/one CL book read-ASP

The first difference between the c-type sentences and the other two types of sentences is that c-type sentences are opaque to the specificity effect and thus are able to undergo object shift and topicalization, as shown in (32).

a. wo kan-le shu san ben.

[c-type]

I read-ASP book three $\mathrm{CL}$

'I read three books.'

b. $\quad \mathrm{shu}_{\mathrm{i}}$ wo kan-le $\mathrm{t}_{\mathrm{i}}$ san ben. [c-type, topicalized]

book I read-ASP three CL

c. wo shu in $_{\mathrm{i}}$ kan-le $t_{\mathrm{i}}$ san ben.[c-type, object shifted]

I book read-ASP three $\mathrm{CL}$

\footnotetext{
${ }^{10}$ Pre-numeral NPs in non-predicative constructions are not derived from VP-internal NP raising (J. Tang 1996 and Zhang 1999a). Thus the pre-numeral NPs in sentences like (30c) are base-generated to the left of the numerals.
} 
In contrast, direct objects in a-type and b-type sentences are indefinite and thus unable to undergo object shift and topicalization, as shown in (33) and (34).
a. wo mai-le yi ben bijibu sanshi ye. [a-type]
I buy-ASP one CL note-book thirty page
'I bought a notebook, which has thirty pages.'
b. $\quad *$ [yi ben bijibu $]_{i}$ wo mai-le $t_{i}$ sanshi ye. [a-type, topicalized] one CL note-book I buy-ASP thirty page
c. $\quad *$ wo $[y i \text { ben bijibu }]_{i}$ mai-le $t_{i}$ sanshi ye. [a-type, object shifted] I one CL note-book buy-ASP thirty page
a. wo mai-le yi ben shu hen youqu. [b-type]
I buy-ASP one CL book very interesting
'I bought a book, which is very interesting.'
b. *[yi ben shu $]_{i}$ wo mai-le $t_{i}$ hen youqu. [b-type, topicalized] one CL book I buy-ASP very interesting
c. $*_{w o}[y i \text { ben } s h u]_{i}$ mai-le $t_{i}$ hen youqu. [b-type, object shifted] I one CL book buy-ASP very interesting

Second, the direct objects of c-type sentences must be bare NPs, while those of a-type and b-type sentences can have left peripheral numerals and classifiers (indefinite DPs).

Third, if the complement is a NumP, the classifier in the NumP must agree with the direct object in c-type sentences, but not in a-type and b-type sentences. In the above data, the classifier $z h i$ agrees with the object $b i$ 'pen' in (30c), while the classifier ye does not agree with the object bijibu 'notebook' in (30a). Notebooks are counted by the classifier ben or ge in Chinese.

Fourth, the complement of c-type sentences must be a NumP (Zhang 1999a section 2.4), while that of a-type and b-type sentences can also be an AP. The following data show that if we change the NumP complement of (30a) into an AP, the sentence is still acceptable; however, if we change the NumP complement of (30c) into an AP, the sentence becomes unacceptable:
a. wo mai-le yi ben bijibu hen pianyi. I buy-ASP one CL note-book very cheap 'I bought a notebook, which is cheap.'
c. *wo mai-le bijibu hen pianyi. I buy-ASP note-book very cheap

Fifth, the post-verbal part of c-type sentences cannot be conjoined with that of a/b-type sentences. Two a-type secondary predication constructions are conjoined in (36a), and two ctype secondary predication constructions are conjoined in (36b). In (36c) a c-type secondary predication and an a-type secondary predication constructions are conjoined, which renders the sentence unacceptable.

(36) a. wo mai-le yi ben bijibu sanshi ye, yi ge rijiben sishi ye. I buy-ASP one CL note-book thirty page one CL diary-book fourty page 'I bought a notebook, which has 30 pages, and a diarybook, which has 40 pages.'

b. wo mai-le bi shi zhi, xiangpi san kuair. I buy-ASP pen ten CL rubber-eraser three CL 'I bought ten pens, and three rubber-erasers.' 
c. *wo mai-le bi shi zhi, yi ben bijibu sanshi ye.

I buy-ASP pen ten $\mathrm{CL}$ one $\mathrm{CL}$ note-book thirty page

Intended: 'I bought ten pens, and a notebook, which has thirty pages.'

If two elements can be conjoined, it does not ensue that they have identical structures (Munn, Forthcoming). However, if two elements cannot be conjoined, they must have different syntactic or semantic structures. Data like (36c) indicate that although both c-type and a-type sentences have postverbal nominals and NumPs, they differ in structures.

The above five aspects clearly distinguish c-type sentences from a-type and b-type sentences. However, there are two shared properties which distinguish secondary predication constructions from non-complex predication constructions. The first one is that neither type can contain a duration or frequency expression. To capture this property, I assume that there is neither NumP nor ClP between $\mathrm{VP}$ and VP in a secondary predication construction (cf. (18a) above). The second shared property of secondary predication construcitons is the absence of an object expletice ta (ge). In Zhang (1999a) I assume that the object expletive takes the position of Spec of TransP. I will show that in secondary predication constructions, this position is either unavailable, since TransP is not projected, or filled. ${ }^{1 /}$

Following Larson (1988), I assume that objects are generated at Spec positions and that complement positions are reserved for non-object complements. A complement NumP differs from an argument NumP in that the ClP, which is selected by Num in Chinese (Li 1997), does not select an NP. Presumably, non-argument NumPs do not participate theta role assigning, or theta feature checking in the sense of Hornstein (1999).

I assume while objects of c-type sentences are base-generated at Spec of TransP, which takes VP as complement, objects of a-type and b-type sentences are base-generated at Spec of VP. In addition, a-type and b-type sentences do not project TransP.

Object depictive secondary predication can also be found in English:

The Japanese eat all their fish raw.

Following Stowell (1981) and Veenstra's (1996: 68) assumption that such constructions have a small clause, I propose that in a-type and b-type sentences a small clause adjoins to the VP.

The structure of the a-type secondary predication is illustrated in (38). The nominal $y i$ ge bijibu 'one CL notebook' is an indefinite DP object at Spec of VP, a VP-internal position, and sanshi ye 'thirty pages' is a NumP predicate of a small clause which adjoins to the matrix $\mathrm{V}$, as shown in (38b).

a. wo mai-le yi ben bijibu sanshi ye.

I buy-ASP one CL note-book thirty page

'I bought a notebook, which has thirty pages.'

\footnotetext{
${ }^{11}$ In fact the two properties, namely lack of an object expletive and lack of a duration/frequency expression, are also seen in other complex predicates, as shown in the following serial verb construction:

(i) a. ta na-le yi ge xiangzi lai.

he take-ASP one CL suitcase come

'He brought a suitcase over.'

b. *ta na-le ta (ge) yi ge xiangzi lai. he take-ASP it one CL suitcase come

c. *ta na-le nei ge xiangzi lai san ci.

he take-ASP that-one CL suitcase come three time
} 
b.

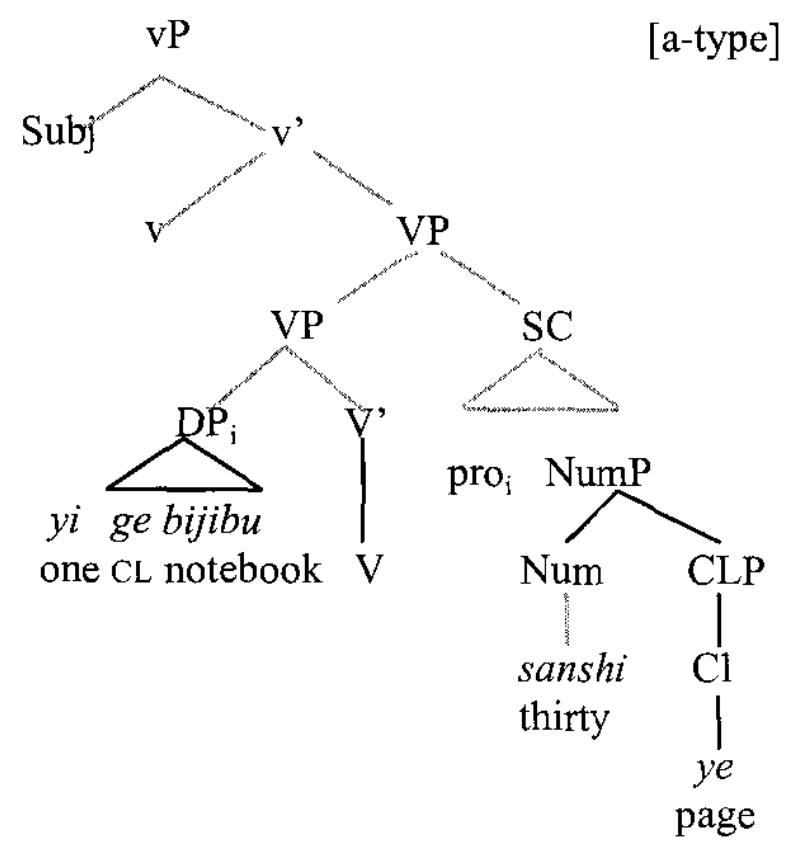

The structure of the b-type secondary predication is illustrated in (39). The nominal $y i$ ge bijibu 'one CL notebook' is an indefinite DP object at Spec of VP, a VP-internal position, and hen piaoliang 'very beautiful' is an AP predicate of a small clause which adjoins to the matrix $\mathrm{V}$, as shown in (39b).

(39) a. wo mail-le yi ben bijibu hen piaoliang. I buy-ASP one CL note-book very beautiful 'I bought a notebook, which is very beautiful.'

b.

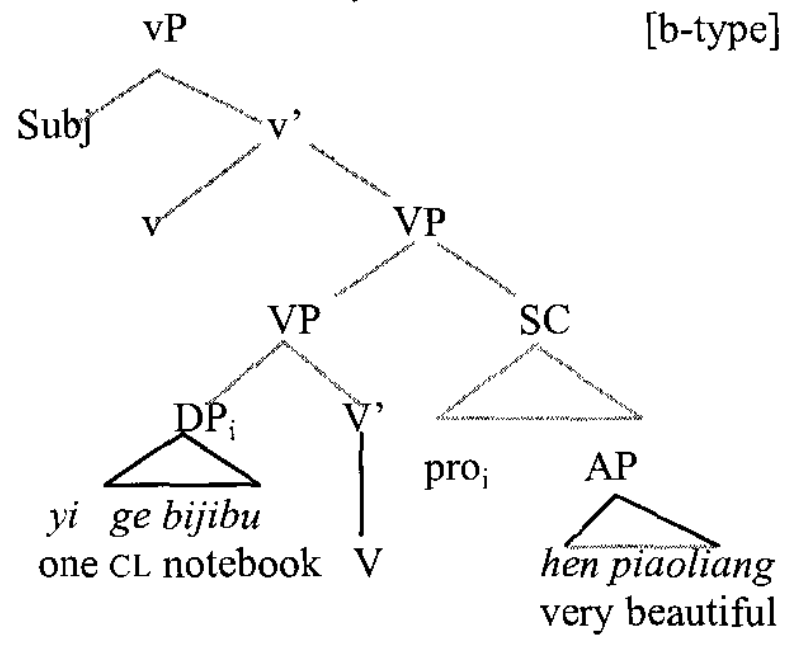

The structuroe of the c-type secondary predication is illustrated in (40). The nominal bijibu 'notebook' is kind-denoting bare NP object at Spec of TransP, a VP-external position, and sanshi ge 'thirty $\mathrm{CL}^{\prime}$ ' is a NumP which is a complement of $\mathrm{V}$, as shown in (40b).

(40) a. wo mail-le bijibu shanshi ge.

I buy-ASP notebook thirty

$\mathrm{CL}$

'I bought thirty notebooks.' 
b.

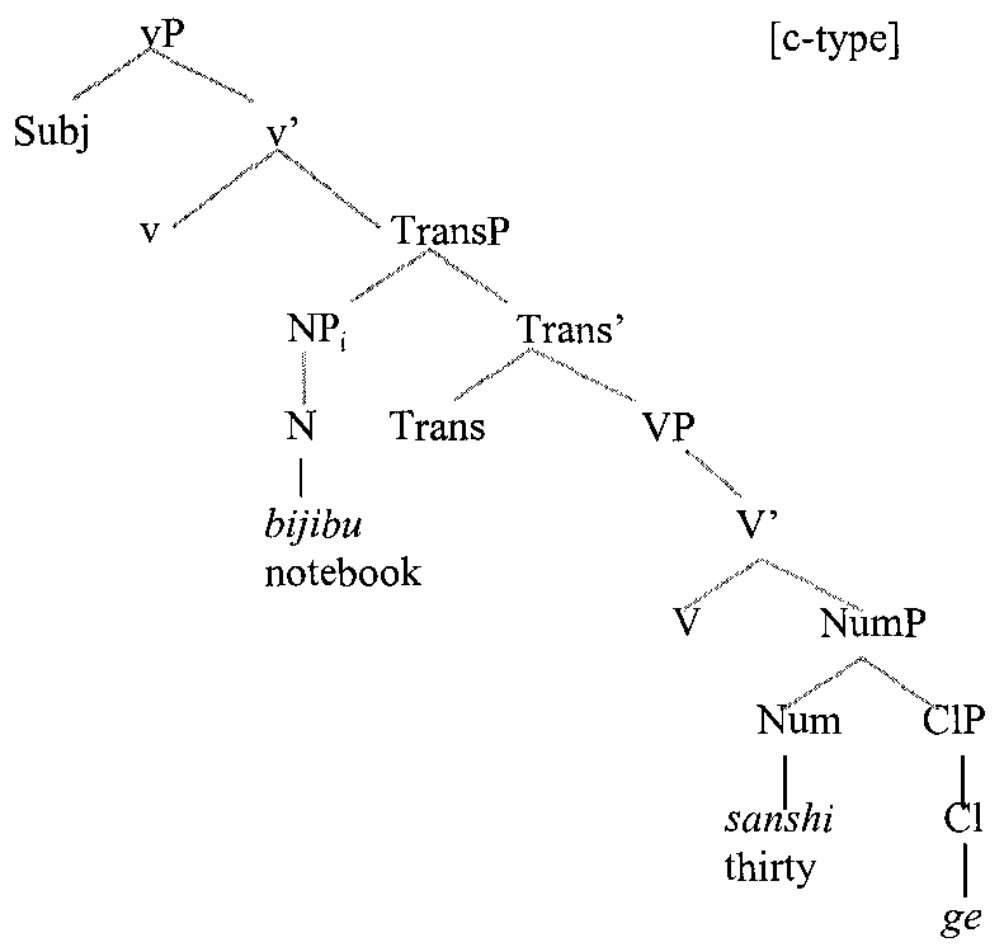

My above assumption captures the topicalization and object shift fact, since external objects are kind-denoting nominals and thus opaque to the specificity effect, which occurs only in individual-denoting nominals, and thus can undergo the two types of movement, while internal objects are individual-denoting nominals, sensitive to the specificity effect, and thus indefinite objects cannot undergo the two types of movement. My assumption also captures the categorial difference fact, in the way that the object in (38) is an indefinite DP and that in (40b) is a bare NP

Furthermore, this assumption covers the agreement fact. An agreement between a nominal and a classifier is required in either individual counting or individuation. Type $c$ of the secondary predication belongs to the latter case, namely, the bare NP object is a kinddenoting argument and the NumP individuates the referent of the NP (Zhang 1999a). Thus $\mathrm{NP}$-Classifier agreement is required. In (40b) the agreement feature of $\mathrm{Cl}$ is perculated to TransP, and the NP, which is at Spec of TransP, can have a checking relationship with the perculated agreement feature. In type-a secondary predication, in contrast, neither individual counting nor individuation is involved. The NumP sanshi ye 'thirty page' is not used to count the number of the notebooks, neither does it individuate the referent of the DP, since a DP is already an individual denoting category (Li 1998). Instead, the NumP in type-a secondary predication describes some quantity property of the individual expressed by the DP object. In (30a), repeated here as (41a), the NumP tells us that the notebook has thirty pages. The word ye 'page' is used as a measure word rather than a classifier here. In (41b), the NumP tells us that the fish weighs five kilograms, and the measure word gongjin 'kilogram' heads the ClP.

(41) a. wo mai-le yi ben bijibu sanshi ye.

I buy-ASP one CL note-book thirty page

'I bought a notebook, which has thirty pages.'

b. wo mai-le yi tiao yu wu gongjin.

I buy-ASP one CL fish five $\mathrm{kg}$

'I bought a fish, which has five kilograms.'

Fourthly, our assumption accounts for the different category restriction on sentencefinal complements between c-type sentences and a/b-type sentences. External objects are 
kind-denoting arguments and thus require NumP predicates (see Zhang 1999a section 2.4), while internal objects are individual-denoting arguments and thus do not require their predicates to be NumPs.

Fifthly, our assumption explains the conjunction fact. If the base-position of objects of c-type sentences differs from that of objects of $a / b$-type sentences, the two types of sentences have different internal structures and thus constituents of one type cannot conjoin with that of the other type.

Finally, the object expletive $t a$ ( $g e$ ), which takes the position of Spec of TrasP as assumed in Zhang (1999a), is ruled out in all three types of secondary predication, since TransP does not project in the a-type and b-type of secondary predication and Spec of TransP has been taken by the object in the c-type of secondary predication.

Our analysis shows that there are two types of secondary predication construction. The one illustrated by the c-type sentences, has base-generated VP-external objects. In contrast, the one illustrated by the a-type and b-type sentences, has base-generated VP-internal objects.

\subsection{The ban of null verbs in the internal-object type of secondary predication}

The following data show that only the external object type of secondary predication is allowed to have gapped verbs:
a. *Lao Hu mai-le yi ge bijibu ershi ye, Lao Li yi ge rijiben wushi ye. Lao Hu buy-ASP one CL notebook 20 page Lao Li one CL diary-book 50 page
b. *Lao Hu mai-le yi jian chenshan hen da, Lao Li yi tiao qunzi hen duan. Lao Hu buy-ASP one CL shirt very big Lao Li one CL skirt very short
a. ta chi-le pingguo yi ge, wo juzi liang ge. he eat-ASP apple one CL I orange two $\mathrm{CL}$ 'He ate one apple and I two oranges.'
b. chuang-shang shu san ben, chuang-xia zhaopian si zhang. bed-on book one CL bed-below photo four $\mathrm{CL}$ 'There are three books on the bed and four photos below the bed.'

(42a) is an a-type secondary predication construction, and (42b) is a b-type secondary predication construction. Neither can have verb gapping. In contrast, the two sentences in (43) are c-type predication constructions and allow for verb gapping.

\section{Conclusions}

In this paper I have described the syntactic contrasts between verbless constructions and constructions with overt verbs in Chinese. I first presented data showing that in both predicative and non-predicative constructions, Chinese pre-numeral nominals can be derived by movement, and the movement is optional in the presence of overt verbs and obligatory in the absence of overt verbs. In addition, verbless constructions cannot have indefinite internal arguments, while constructions with overt verbs can. Furthermore, there are two types of secondary predication constructions in Chinese, one with a bare NP object and the other with 
an indefinite DP object, and only the former type allows verb gapping. All of these contrasts remain to be explained.

\section{References}

Chao, Wynn (1987) On ellipsis. PhD thesis, Umass: Amherst. Published 1988 by Garland.

Chierchia, Gennaro (1998) Reference to kinds across languages. Natural Language Semantics 6: 339-405.

Hornstein, N. (1999) Movement and control, Linguistic Inquiry 30, 69-96.

Hou, Xuechao (1998) Xiandai Hanyu Xuci Cidian [a dictionary of functional words of modern Chinese]. Beijing: Beijing University Press.

Huang, C.-T. James (1994) More on Chinese word order and parametric theory. B. Lust, M. Suner and J. Whitman (eds.) Santactic Theory and First Language Adquisition: Crosslinguistic Perspectives, vol. 1, Heads, Projections and Learnability, Lawrence Erlbaum Associates, Inc.

Johnson, Kyle (1994) Bridging the gap. Ms. University of Massachusetts, Amherst.

Kayne, R. (1994) The Antisymmetry of syntax. MIT Press.

Larson, R. (1988) On the double object construction. Linguistic Inquiry 19, 335-391.

$\mathrm{Li}$, Yen-hui Audrey (1997) Structures and interpretations of nominal expressions, handout of the presentation at NACCL-9, University of Victoria.

- (1998) Argument Determiner Phrases and Number Phrases. Linguistic Inquiry 29, 693-702.

- (1999) Minimal $\alpha$, presented at the workshop on Adding \& Omitting, Konstanz, Feb. 24-26, 1999.

Lin, Jo-Wang (1993) Object expletives in Chinese. Presented at NACCL 5, University of Delaware.

Longobardi, G. (1994) Reference and proper names, Linguistic Inquiry 25: 609-66.

Lü, Shuxiang et al. (1980) Xiandai Hanyu Babai Ci [800 Grammatical Words in Modern Chinese], Shangwu Yinshuguan, Beijing.

Ma, Qingzhu (1983) Xiandai Hanyu de shuangbinyu gouzao [the structures of the double object construction in modern Chinese] Yuyanxue Luncong 10, Shangwu Press, Beijing.

- (1991) Shunxuyi dui tici yufa gongneng de yingxiang [The influence of ordinal meaning on the grammatical functions of substantivals]. Zhongguo Yuyanxue Bao [Journal of Chinese Linguistics] 4, 59-83. Beijing: Shangwu Press.

Munn, Alan (Forthcoming) Three types of coordination asymmetries. In Kerstin Schwabe \& Ning Zhang eds., Ellipsis in Conjunction, Tübingen: Niemeyer.

Paul, Waltraud (1996) Verb raising in Chinese. In Chin-chuan Cheng et al eds., Proceedings of the 8th North American Conference on Chinese Linguistics, Vol. 1, 260-276. Los Angeles: Graduate Students in Linguistics, USC.

Radford, A. (1997) Syntactic theory and the structure of English: A minimalist approach. Cambridge: University Press.

Stowell (1981) Origins of phras structure. PhD. dissertation, MIT.

Tang, Chih-Chen Jane (1996) ta mai-le bi shi-zhi and Chinese phrase structure, Bulletin of the Institute of History and Philology, Academia Sinica, Taibei, 67 (3): 445-501.

Tang, Sze-Wing (1998) 'Parametrization of Features in Syntax', Doctoral dissertation, University of California, Irvine.

Veenstra, Tonjes (1996) Serial verbs in Saramaccan: predication and creole genesis. PhD dissertation, University of Amsterdam.

Zhang, N. Ning (1997) Verb gapping in Chinese. ZAS Papers in Linguistics. Vol. 9. 145-165.

- (To appear a) Object Shift in Mandarin Chinese. Journal of Chinese Linguistics.

- To appear b. A Review of the Dissertation 'Parametrization of Features in Syntax' by Sze-Wing Tang. Glot International.

- (1999a) External objects and kind-denoting arguments. Ms. ZAS.

- (1999b) Counting and measuring eventualities in Chinese. Ms. ZAS.

Zhu, Dexi (1984) Yufa jiangyi [Lectures on grammar]. Beijing: Shangwu Press. 